\title{
Acute Erythroblastic Leukemia Revealed by Dermatological Manifestations
}

\section{K Moustaide*, A Nassiri, S Gallouj and FZ Mernissi}

University Hospital Hassan II, North Africa

Received: 非 February 17, 2018; Published: 制 February 21, 2018

*Corresponding author: Kaoutar Moustaide, University Hospital Hassan II, Route sidi Hrazem Fes, North Africa

\section{Abstract}

Acute erythroblastic leukemia is characterized by the proliferation of a predominant erythrocyte population on other lineages. Cutaneous manifestations remain rare and misleading, making the diagnosis of difficult to suspect as first-line. Here, we report an unusual and rare case of acute leukemia in a 24 year old male with gingival hypertrophy and dermatological manifestations. This case emphasizes that dentist and dermatologist should be well acquainted with these manifestations of systemic diseases.

\section{Case Report}

We report the case of 24 years old patient, with no significant pathological history, who had a rash for 10 days in a context of fever and very bad general condition. At admission the patient was febrile, tachycardic and dyspneic. Physical examination revealed erythemato-purplished papulo-nodules on the face, trunk, limbs and a gingival hyperplasia. The oral state was deplorable. Bilateral cervical lymphadenopathy was also found without the patosplenomegaly (Figures 1-3). The biological assessment showed a CRP of 150 and a pancytopenia with a Hbat 7.5g / dl, normal VGM and CCMH, a deep thrombocytopeniaat 85000 / l, leukocytesat 1500 / l. The blood smear showed 35\% of circulating blasts and $22 \%$ of erythroblasts (Figure 4 ).
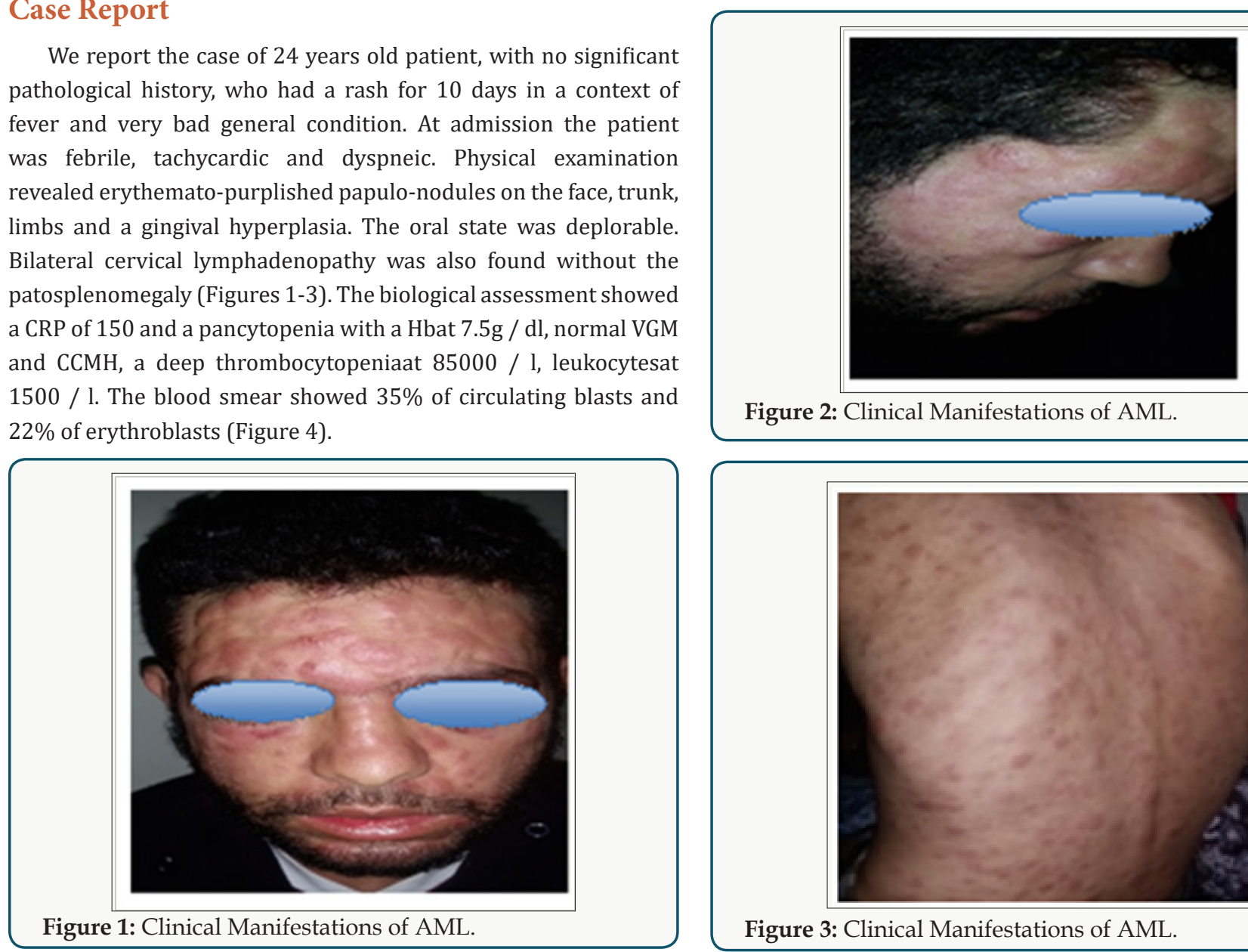

Figure 2: Clinical Manifestations of AML.

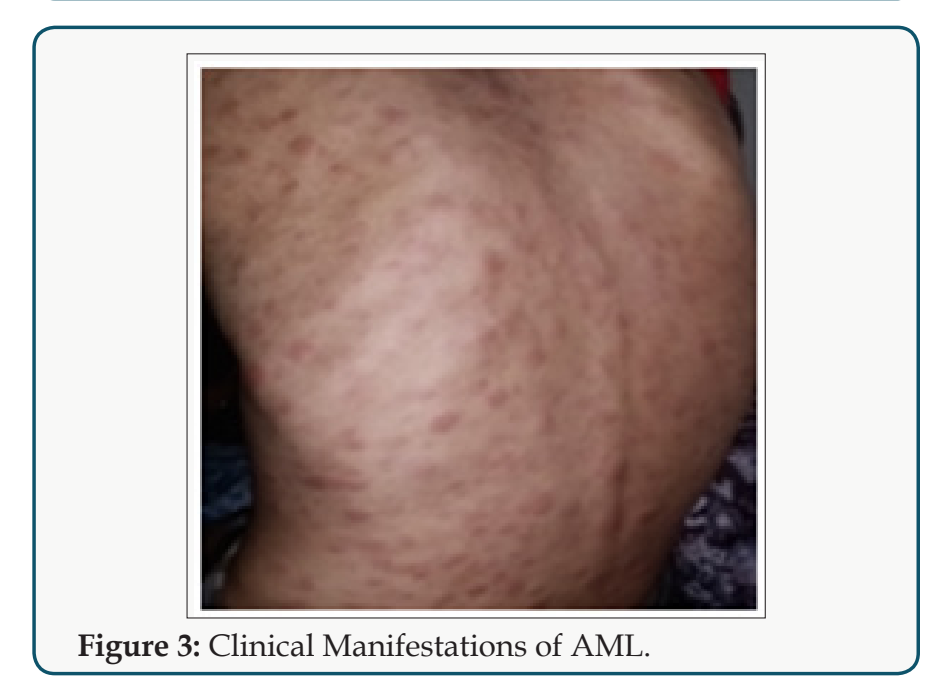




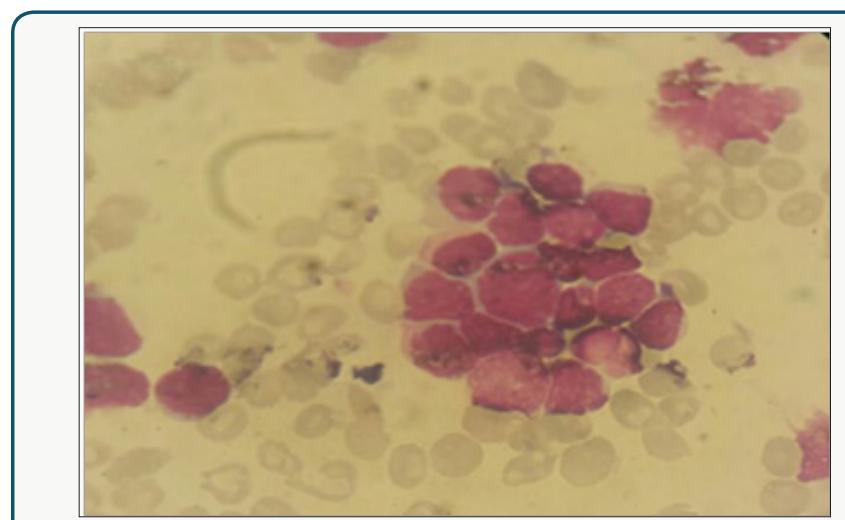

Figure 4: Blood smear showing 35\% of circulating blasts.

The medullo gram showed a hyper-cellular marrow with a rate of myeloblasts greater than $45 \%$ compared to all non-erythroblastic elements and erythroblastic hyperplasia estimated at more than $65 \%$; with signs of dyserythropoiesis suggestive of the diagnosis of erythroleukemia (Figure 5). Blood immune phenol typing was positive for CD13, CD33, MPO and Glycophotin A. The evolution was unfavourable; the patient died due to massive alveolarhemorrhage.

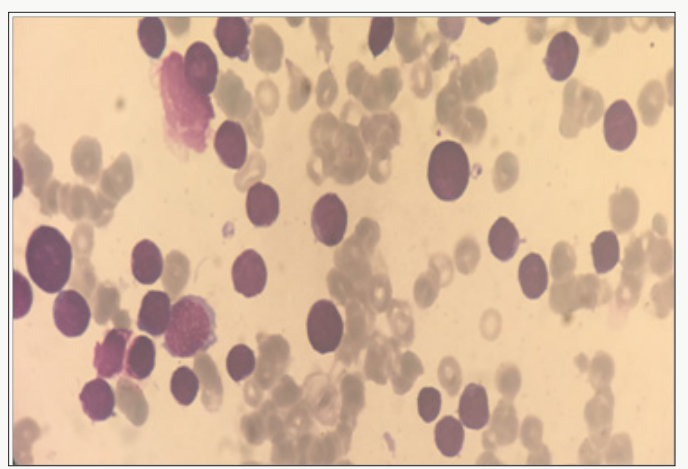

Figure 5: Hyper cellular marrow infiltrated by a blastic contingent estimated at $45 \%$.

\section{Discussion}

Acute erythroblastic leukemia is characterized by the proliferation of a pre dominantery throcyte population on other lineages. There are two types: Erythroleukemia: defined by the presence in the bone marrow of more than $50 \%$ of the erythroid precursors of all the medullary cells, and more than $20 \%$ of myeloblasts of the whole non-erythrocytemedullary cells - Pure erythroid leukemia: it presents a neoplastic proliferation made of more than $80 \%$ of erythrocyte cells without obvious presence of the myeloblastic contingent [1]. It is usually manifested by signs of bone marrow failure and cytopenia [2,3], skin involvement remains rare, varied and disorienting the diagnosis; they are found mainly in Acute myelovlastic leukemia [4,5]. Cutaneous manifestations during leukemia are infrequent and varied. They designate all the cutaneouslesions related to the haematological malignancy directly or indirectly following their treatment; we essentially distinguish.

The specific dermatological lesions which can reveal hematological diseases [4], are mainly represented by leukaemides (leukaemia cutis), which are red brown to purple dermal papules, plaques or nodules. Granulocyticsarcom as an extra-medullary tumour masses, ulcerated plaques and gingival hypertrophy [5]. The infectious dermatoses secondary to the biological disturbances accompanying the malignan themopathy and their treatments. The occurrence of specific cutaneouslesions in leukemia is synonymous with a major aggravation of the prognosis (with for example a survival twice as short if there is a specific cutaneous involvement); this seriousness make some authors propose different treatments with a medium-long stay hospitalization[6-8].

In our case, acute myelonlastic leukemia 6 (AML 6 ) was revealed by diffuse leukemias resulting from the infiltration and proliferation of malignantha ematological cells (blasts) in the skin and by gingival hyperplasia secondary to mucosal infiltration [5]. The clinical presentation of acute leukemia including AML6 in the form of ulcer ativenecroticgingivitis in the foreground, is a rare form to be remembered, mentioned in all courses of medicine and dentistry, stipulating that Gingival involvement is a classic feature of leukemia [6] The frequent association of skin cancers with haematological malignancies is also highlighted in several publications [5].

\section{Conclusion}

The cutaneous localizations are among the rarest extreme dullary lesions of acute myeloid leukaemia's (AML) not exceeding $1 \%$. They are generally considered as factors of worse prognosis. Their cytogenetic or mutational specificities remain un established to date.

\section{References}

1. Imane Tlamçani, Salma Benjelloun, Ghita Yahyaoui, Moncef Hassani Amrani (2014) Leucémie aigue érythroblastique: à propos de sept observations. The Pan African Medical Journal Published: 18/05/2014.

2. Killick S, Matutes E (2002) Acute Erythroid leukaemias. Atlas Genet Cytogenet Oncol Haematol.

3. Killick S, Matutes E, Powles RL, Min T, Treleaven JG, et al. (2014) La leuc émie aigue érythroïde (M6): résultat de la transplantation de moelle osseuse. Leukemia and Lymphoma.

4. Blessis D, Frances C, Grillot J (2009) manifestations dermatologiques des maldies du système hématologique et oncologie dermatologique. Dermatologie et medicine, Springer Verlag, France.

5. H Bay BayLes (2011) manifestations cutanées au cours des hémopathies malignes, EM consulte.

6. Arnaud Lafon, Thomas Belangeon, Victorin Ahossi, Patrick Larras, Daniel Perri, et al. (2010) Leucémie aiguë myéloïde : le tableau clinique est parfois trompeur. Service d'Odontologie, MBCB Journal.

7. Dan Lipsker, PeggyBoeckler (2007) Manifestations cutanées associées aux paraproteines,mechanism e des atteintes cutanées, La Presse Médicale 36(8): 1135-1140.

8. Namba Y, Koizumi H, Nakamura H, Taromi T, Sawada K, et al. (1999) Specific cutaneous lesions of the scalp in myodysplastic syndrome with deletion of 20q. J Dermatol 26(4): 220-224. 
(C) This work is licensed under Creative To Submit Your Article Click Here:

Submit Article

DOI: 10.32474/OAJOM.2018.01.000106

\section{Open Access Journal of Oncology and Medicine}

\section{OAJOM}

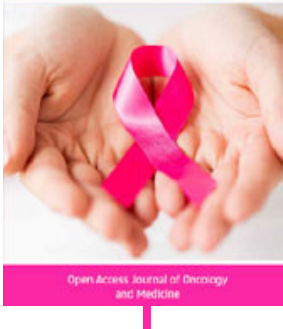

\section{Assets of Publishing with us}

- Global archiving of articles

- Immediate, unrestricted online access

- Rigorous Peer Review Process

- Authors Retain Copyrights

- Unique DOI for all articles 